\title{
The most important animal pest is the possibility of transmitting or reservoirs the Corona virus
}

Abd El-Aleem Saad Soliman Desoky

Plant protection Department (Agricultural Zoology), Faculty of Agriculture, Sohag University, Egypt.

Corresponding Author: Abd El-Aleem Saad Soliman Desoky, Plant protection Department (Agricultural Zoology), Faculty of Agriculture, Sohag University, Egypt.

Received date: April 22, 2021; Accepted date: June 08, 2021; Published date: June 11, 2021

Citation: Abd El-ASS Desoky. (2021) The most important animal pest is the possibility of transmitting or reservoirs the Corona virus. Biomedical Research and Clinical Reviews. 4(2); DOI: 10.31579/2692-9406/059

Copyright: (C) 2021 Abd El-Aleem Saad Soliman Desoky, This is an open-access article distributed under the terms of the Creative Commons Attribution License, which permits unrestricted use, distribution, and reproduction in any medium, provided the original author and source are credited.

\begin{abstract}
Although the bat has unique characteristics compared to other mammals, but it currently enjoys a poor reputation, especially after being linked to being the source of the Corona virus, as international researchers recently published a large-scale research, which is the largest of its kind, about corona viruses in the bat, If this hypothesis is correct, then the Corona virus will be added to other dangerous viruses carried by the bat bird. The bird had caused, years ago, the spread of viruses such as "SARS" and "MERS", because the bat can carry different viruses without getting sick. The bat is a "reservoir for viruses" that have caused a number of diseases and epidemics in Africa, Malaysia, Bangladesh and Australia. It is not limited to the mentioned viruses, as the bat carries an "Ebola" infection, and the "rabies" virus also carries. Other mammals. It is possible that other animal pests such as rodents may be related to reservoiror transmitting the Corona virus.
\end{abstract}

Keywords: bat; corona viruses; SARS; MERS; Ebola; rabies; reservoir for viruses

\section{Introduction}

Bats have been recognized as the natural reservoirs of a large variety of viruses. Special attention has been paid to bat coronaviruses as the two emerging coronaviruses which have caused unexpected human disease outbreaks in the 21st century, Severe Acute Respiratory Syndrome Coronavirus (SARS-CoV) and Middle East Respiratory Syndrome Coronavirus (MERS-CoV), are suggested to be originated from bats. Various species of horseshoe bats in China have been found to harbor genetically diverse SARS-like coronaviruses. Some strains are highly similar to SARS-CoV even in the spike protein and are able to use the same receptor as SARS-CoV for cell entry. On the other hand, diverse coronaviruses phylogenetically related to MERS-CoV have been discovered worldwide in a wide range of bat species, some of which can be classified to the same coronavirus species as MERS-CoV. Coronaviruses genetically related to human coronavirus 229E and NL63 have been detected in bats as well. Moreover, intermediate hosts are believed to play an important role in the transmission and emergence of these coronaviruses from bats to humans. Understanding the bat origin of human coronaviruses is helpful for the prediction and prevention of another pandemic emergence in the future Ben Hu et al (2015).

Rodents are the most diverse mammals on the planet and are important reservoirs of many pathogens example Coronaviruses infect various animals, but to date, relatively few coronaviruses have been identified in rodents worldwide. Rat coronaviruses are very contagious, with transfer to susceptible rats by direct contact with infected rats, and indirectly by aerosol and fomites. The evolution and ecology of coronaviruses in rodent have not been fully investigated to human. Desoky (2020).

\section{Background}

Banerjee et al., (2019) They found,bats are speculated to be reservoirs of several emerging viruses including coronaviruses $(\mathrm{CoVs})$ that cause serious disease in humans and agricultural animals. These include $\mathrm{CoVs}$ that cause severe acute respiratory syndrome (SARS), Middle East respiratory syndrome (MERS), porcine epidemic diarrhea (PED) and severe acute diarrhea syndrome (SADS). Bats that are naturally infected or experimentally infected do not demonstrate clinical signs of disease. These observations have allowed researchers to speculate that bats are the likely reservoirs or ancestral hosts for several CoVs. In this review, we follow the $\mathrm{CoV}$ outbreaks that are speculated to have originated in bats. We review studies that have allowed researchers to identify unique adaptation in bats that may allow them to harbor CoVs without severe disease. We speculate about future studies that are critical to identify how bats can harbor multiple strains of CoVs and factors that enable these viruses to "jump" from bats to other mammals. We hope that this review will enable readers to identify gaps in knowledge that currently exist and initiate a dialogue amongst bat researchers to share resources to overcome present limitations.

Latinne, et al. (2020).Bats are presumed reservoirs of diverse coronaviruses (CoVs) including progenitors of Severe Acute Respiratory Syndrome (SARS)-CoV and SARS-CoV-2, the causative agent of COVID-19. However, the evolution and diversification of these 
coronaviruses remains poorly understood. Here we use a Bayesian statistical framework and a large sequence data set from bat-CoVs (including 630 novel $\mathrm{CoV}$ sequences) in China to study their macroevolution, cross-species transmission and dispersal. We find that host-switching occurs more frequently and across more distantly related host taxa in alpha- than beta-CoVs, and is more highly constrained by phylogenetic distance for beta-CoVs. We show that inter-family and genus switching is most common in Rhinolophidae and the genus Rhinolophus. Our analyses identify the host taxa and geographic regions that define hotspots of $\mathrm{CoV}$ evolutionary diversity in China that could help target bat-CoV discovery for proactive zoonotic disease surveillance. Finally, we present a phylogenetic analysis suggesting a likely origin for SARS-CoV-2 in Rhinolophus spp. bats.

A novel coronavirus reported to cause pneumonia in 41 people during December 2019 in Wuhan, the capital of Hubei province, China, was identified and designated as the 2019 novel coronavirus (2019-nCoV) (Zhu et al., 2020; Li et al., 2020). Infection with 2019-nCoV results in clusters of severe respiratory illness similar to that caused by severe acute respiratory syndrome coronavirus (SARS-CoV) and is associated with high mortality (Chen et al., 2020; Huang et al., 2020).

After epidemiological investigation, it was revealed that a local seafood market, where wild animals and live poultry were for sale, was linked to this undiagnosed pneumonia ( $\mathrm{Wu}$ et al., 2020). Wu et al. collected bronchoalveolar lavage fluid from a patient who worked in the seafood market and performed full genome sequencing of 2019-nCoV. It was shown that 2019-nCoV had a high nucleotide sequence similarity to a bat SARS-related CoV (bat-SL-CoVZC45, accession No. MG772933) and only $79.5 \%$ genome sequence similarity to SARS-CoV. Phylogenetic analysis showed that the virus was clustered with SARS-CoV and bat SARSr-CoVs in subgenus Sarbecovirus (Wu et al., 2020; Wei et al., 2020; Yu et al., 2019; Xu et al., 2020). Genomic analysis of 2019-nCoV and four typical coronaviruses (bat SARSr-CoV-Rp3, CoV-ZC45, CoVZXC21, and SARS-CoV-Tor2) showed a likelihood of recombination between 2019-nCoV and other coronaviruses among the subgenus (Wu et al., 2020). So how did this novel coronavirus emerge? To investigate the origin of 2019-nCoV, Zhou et al. sequenced samples from seven patients and bats, and found that this new coronavirus shared $96.2 \%$ overall genome sequence identity with a bat coronavirus RaTG13 from horseshoe bats (Rhinolophus). This discovery provided further evidence that 2019nCoV most likely originated from bats (Zhou et al., 2020). Previously, horseshoe bats were identified as natural hosts for SARS-related coronaviruses which were the direct progenitors for the origin of SARSCoV (Hu et al., 2017).

Desoky, (2020) Rodents are important reservoirs of many pathogens example Coronaviruses. The previously infected mice have a lower degree of infection in future periods. The evolution and ecology of coronaviruses in rodent have not been fully investigated to human.A study of the immune system of infected rodents can be used to control the effect of coronaviruses on humans, especially the Coronavirus (COVID-19), it spreads all over the world and causes many deaths in the current period. From this, can also possible to study the immune system of people who have recovered from the disease in search of a new Therapy that useful all of humanity.

\section{References}

1. Banerjee A, Kirsten Kulcsar, Vikram Misra. Matthew Frieman and Karen Mossman. (2019) Review: Bats and Coronaviruses. Viruses 11(1):40.

2. Chen N, Zhou M, Dong X, Qu J, Gong F, Han Y, Qiu Y, Wang J, Liu Y, Wei Y, et al. (2020) Epidemiological and clinical characteristics of 99 cases of 2019 novel coronavirus pneumonia in Wuhan, China: a descriptive study. Lancet.

3. Desoky, A. S. S. (2020). Relationship of Rodents with Corona Viruses Infection- An Overview. Open Access Journal of Pharmaceutical Research. 4(3); 1-2.

4. Hu, B., Zeng, L.P., Yang, X.L., Ge, X.Y., Zhang, W., Li, B., Xie, J.Z., Shen, X.R., Zhang, Y.Z., Wang, N., et al. (2017). Discovery of a rich gene pool of bat SARS-related coronaviruses provides new insights into the origin of SARS coronavirus. PLoS Pathog 13.

5. Hu B, Xingyi Ge, Lin-Fa Wang and Zhengli Shi. (2015) Bat origin of human coronaviruses. Virology Journal. 12:221.

6. Huang, C., Wang, Y., Li, X., Ren, L., Zhao, J., Hu, Y., Zhang, L., Fan, G., Xu, J., Gu, X., et al. (2020) Clinical features of patients infected with 2019 novel coronavirus in Wuhan, China. Lancet.

7. Latinne A., Ben Hu, Kevin J. Olival, Guangjian Zhu, Libiao Zhang, Hongying Li, Aleksei A. Chmura, Hume E. Field, Carlos Zambrana-Torrelio, Jonathan H. Epstein,Bei Li, Wei Zhang, Lin-Fa Wang, Zheng-Li Shi \& Peter Daszak. (2020) Origin and cross-species transmission of bat coronaviruses in China. Nature Communications.

8. Li, Q., Guan, X., Wu, P., Wang, X., Zhou, L., Tong, Y., Ren, R., Leung, K. S.M., Lau, E.H.Y., Wong, J.Y., et al. (2020) Early transmission dynamics in Wuhan, China, of novel coronavirusinfected pneumonia. N Engl J Med.

9. Wei, X., Li, X., and Cui, J. (2020) Evolutionary perspectives on novel coronaviruses identified in pneumonia cases in China. Natl Sci Rev.

10. Wu, F., Zhao, S., Yu, B., Chen, Y.M., Wang, W., Song, Z.G., Hu, Y., Tao, Z. W., Tian, J.H., Pei, Y.Y., et al. (2020) A new coronavirus associated with human respiratory disease in China. Nature.

11. Xu, X., Chen, P., Wang, J., Feng, J., Zhou, H., Li, X., Zhong, W., and Hao, P. (2020) Evolution of the novel coronavirus from the ongoing Wuhan outbreak and modeling of its spike protein for risk of human transmission. Sci China Life Sci

12. Yu, P., Hu, B., Shi, Z.L., and Cui, J. (2019) Geographical structure of bat SARS-related coronaviruses. Infect Genet Evol 69, 224-229.

13. Zhou, P., Yang, X.L., Wang, X.G., Hu, B., Zhang, L., Zhang, W., Si, H.R., Zhu, Y., Li, B., Huang, C.L., et al. (2020)A pneumonia outbreak associated with a new coronavirus of probable bat origin. Nature

14. Zhu, N., Zhang, D., Wang, W., Li, X., Yang, B., Song, J., Zhao, X., Huang, B., Shi, W., Lu, R., et al. (2020). A novel coronavirus from patients with pneumonia in China, 2019. N Engl J Med 
(c) (P)

This work is licensed under Creative Commons Attribution 4.0 License

To Submit Your Article Click Here: Submit Manuscript

DOI: $10.31579 / 2692-9406 / 059$
Ready to submit your research? Choose Auctores and benefit from:

* fast, convenient online submission

* rigorous peer review by experienced research in your field

* rapid publication on acceptance

* authors retain copyrights

* unique DOI for all articles

* immediate, unrestricted online access

At Auctores, research is always in progress.

Learn more www.auctoresonline.org/journals/biomedical-research-andclinical-reviews-- 